\title{
PAULO FreIRE NO ÂMBITO DA PESQUISA: OS CÍRCULOS DIALÓGICOS INVESTIGATIVO- FORMATIVOS COMO POSSIBILIDADE DE REINVENÇÃO DOS CÍRCULOS DE CULTURA E AUTO(TRANS)FORMAÇÃO PERMANENTE COM PROFESSORES
}

\author{
Joze Medianelra dos Santos de Andrade Toniolo \\ Instituto Federal de Educação, Ciência e Tecnologia Farroupilha, \\ Santa Maria, Rio Grande do Sul, Brasil \\ Celso llgo Henz \\ Universidade Federal de Santa Maria (UFSM), Santa Maria, Rio \\ Grande do Sul, Brasil
}

\begin{abstract}
Resumo: O presente artigo objetiva socializar as construções realizadas no âmbito da pesquisa, tomando como base os aportes teóricos de Paulo Freire. Inspirados pelos Círculos de Cultura (FREIRE, 2014), (re)criamos os Círculos Dialógicos Investigativo-formativos como uma proposta epistemológico-política de pesquisa, a partir de oito diferentes movimentos que os constituem: a escuta sensível e o olhar/aguçado; a emersão/imersão das/nas temáticas; o distanciamento/desvelamento da realidade; a descoberta do inacabamento; os diálogos problematizadores; o registro recriativo; a conscientização e a auto(trans)formação, que vai se potencializando e se constituindo em todos os demais movimentos. Durante a realização dos Círculos Dialógicos com os professores esses movimentos vão se tramando dialógica e dialeticamente, visando sempre a auto(trans)formação, tanto do pesquisador líder como dos sujeitos coautores envolvidos na pesquisa.
\end{abstract}

Palavras-chave: Círculos Dialógicos Investigativo-formativos. Auto(trans)formação permanente. Pesquisa. Círculos de Cultura. 


\section{Dialogando sobre a proposta: Os Círculos Dialógicos InVestigativo- FORMATIVOS}

Desafiados pelo contexto educacional e inspirados pelos Círculos de Cultura, nosso Grupo de Estudos e Pesquisa Dialogus: educação, formação e humanização com Paulo Freire, registrado junto à base do CNPq em 2011, começou a ousar, aventurando-se na reinvenção de uma proposta metodológica, a partir da epistemologia de Paulo Freire: os Círculos Dialógicos Investigativo-formativos. Dentre as práxis do grupo, uma das premissas é o estudo e aprofundamento dos pressupostos epistemológico-políticos das obras de Paulo Freire. Já há algum tempo, seus integrantes os assumiam para embasar suas pesquisas e produções. No entanto, quando se tratava da fundamentação teórica para delinear os caminhos metodológicos das pesquisas, o Grupo Dialogus sempre buscava outras vertentes teóricas que se aproximavam da práxis de Paulo Freire, tais como a Pesquisa participante e a Pesquisa-ação.

Partindo das inquietações e estudos, no que se refere aos delineamentos metodológicos da pesquisa com e a partir de Paulo Freire, é que surge a proposição dos Círculos Dialógicos Investigativo-formativos, que não se constitui apenas em uma metodologia; ela se configura em uma proposta epistemológico-política que vem sendo construída e assumida pelo grupo, orientando a dinamização dos encontros de estudo e pesquisa, bem como as formações permanentes com os educadores das escolas da Educação Básica e demais projetos. Além disso, por ser uma proposta que vem sendo construída e assumida cooperativamente, com os diferentes interlocutores, muitas pesquisas de mestrado e doutorado já realizadas ou em andamento vêm estudando e aprofundando a sua viabilidade como práxis de pesquisa com professores.

A proposta adotada nos Círculos Dialógicos segue a dinâmica e a intencionalidade epistemológico-política dos Círculos de Cultura de Paulo Freire (2014) em aproximação com a "pesquisa-formação" proposta por MarieChristine Josso (2010), constituindo-se em uma roda de pessoas, sem uma hierarquia de saberes maiores ou menores, mas saberes que se entrelaçam no grupo e, juntos, a partir do diálogo problematizador, cooperativamente, vão desvelando a realidade com consciência crítica e transformadora. Para a realização das pesquisas com os professores, propõe-se a realização de encontros grupais (para o mestrado sugere-se um mínimo de seis e para o doutorado um mínimo de dez), numa reinvenção dos Círculos de Cultura, realizados nas práxis freireanas. Nessa dinamicidade é que: 
O círculo de cultura - no método Paulo Freire - revive a vida em profundidade crítica. A consciência emerge do mundo vivido, objetiva-o, problematiza-o, compreende-o como projeto humano. Em diálogo circular, intersubjetivando-se mais e mais, vai assumindo, criticamente, o dinamismo de sua subjetividade criadora. Todos juntos, em círculo, e em colaboração, re-elaboram o mundo (FIORI, 2014, p. 24).

A originalidade dos Círculos de Cultura propostos por Freire, e problematizados/contextualizados pelo filósofo Ernani Maria Fiori no prefácio da obra Pedagogia do Oprimido (2014), rompe com a concepção bancária e com o modelo tradicional de educação, de escola, de ordem, de disciplina, numa relação cooperativa e de reciprocidades. Diante de muitas pesquisas "bancárias" sobre a formação de professores, os Círculos Dialógicos Investigativo-formativos propõem a perspectiva de uma "pesquisa-formação" (JOSSO, 2010) com os professores; os interlocutores/coautores da pesquisa aparecem nesse contexto como pessoas que ensinam e aprendem, uns em comunhão com os outros, capazes de construir e sistematizar conhecimentos e serem os sujeitos da sua auto(trans)formação e da (re)elaboração do mundo.

Por entender que o processo de pesquisa e de construção do conhecimento se estabelece na relação com os outros, intersubjetivamente, os participantes da pesquisa são desafiados a se reconhecerem e assumirem como coautores, com a participação dialógica de um pesquisador líder. Assim, não existe a figura de alguém que sabe mais, mas de um coordenador do diálogo que vai (inter)mediando as relações que vão sendo estabelecidas no e com o grupo, partindo do princípio de que "no círculo de cultura [...] aprende-se em 'reciprocidades de consciências'; não há professor, há um coordenador, que tem por função propiciar condições favoráveis à dinâmica do grupo, reduzindo ao mínimo sua intervenção direta no curso do diálogo" (FIORI, 2014, p. 15).

Assim, também nos Círculos Dialógicos Investigativo-formativos não se ensina, aprende-se em "reciprocidade de consciências" (FIORI, 2014, p. 15), na qual os sujeitos coautores, ao refletirem sobre a sua própria prática, buscam evidenciar as contribuições desses diálogos construídos com o grupo na sua auto(trans)formação permanente. Além disso, esses momentos formativos dialógicos se constituem em espaços de compartilhamento de vivências e práticas educativas escolares, a fim de (re)significá-las, sempre articuladas aos pressupostos epistemológico-políticos freireanos.

Nos encontros de pesquisa com os professores tem um coordenador que dinamiza e media os diálogos problematizadores e as temáticas geradoras, buscando desafiar uma reflexão crítica com o grupo de interlocutores/ 
coautores, intervindo minimamente, tendo como foco a temática que orienta os processos investigativo-formativos propostos. Os Círculos de Cultura não têm a pretensão de ser uma técnica de pesquisa previamente elaborada para ser aplicada, mas fazer do diálogo a própria diretriz de uma experiência (BRANDÃO, 2010), geradora de uma ação-reflexão-ação problematizadora, de onde emergem novos conhecimentos e a possibilidade de auto(trans) formação por meio da partilha de experiências, da reflexão sobre elas e da constante busca de subsídios teóricos num permanente aprender a "dizer a sua palavra" (FIORI, 2014). Palavra, essa, geradora de cultura, de saberes, de vida, que diz muito da realidade vivenciada por homens e mulheres, potencializadora de novos horizontes, novas sistematizações e que fazeres auto(trans)formativos e educativos.

Essa proposta epistemológico-política vem sendo estudada e assumida pelo Grupo de Estudos e Pesquisa Dialogus, não como um método a ser seguido, mas como uma opção teórico-metodológica a ser reconstruída, repensada, recriada, a partir da realidade histórica, contextualizada, que for se apresentando por meio do diálogo, atentando para o fato de que "o mesmo trabalho coletivo de construir o método, a cada vez, deve ser também o trabalho de ajustar, inovar e criar a partir dele" (BRANDÃO, 2013, p. 68). Esse sempre foi um pressuposto de Freire, afirmando que o método não se impõe sobre a realidade, sobre cada caso, mas ele serve a cada nova situação, por isso a necessidade de reinventá-lo. Em conversa com Faundez, Freire ratifica esse posicionamento, afirmando que "[...] a única maneira que alguém tem de aplicar, no seu contexto, alguma das proposições que fiz é exatamente refazer-me, quer dizer, não seguir-me. Para seguir-me, o fundamental é não seguir-me" (FREIRE; FAUNDEZ, 2002, p. 41).

Na obra O que é método Paulo Freire (BRANDÃO, 2013), fica evidente o desejo de Freire de não transformar sua proposta em um método rígido, não existindo como uma lógica dada a priori ou uma ordem preestabelecida para o ato de ensinar e aprender. Assim também a proposta dos Círculos Dialógicos Investigativo-formativos se apresenta como uma proposta de trabalho-diálogo (BRANDÃO, 2013), tomando o diálogo problematizador como práxis pedagógica, epistemológica e política.

Em cada proposta construída com um novo grupo essa premissa é retomada e reafirmada para que todos os participantes se assumam como coautores, a partir dos seus contextos, buscando uma leitura crítica da realidade social e educacional, sempre respeitando a forma própria de cada grupo se organizar para melhor dinamizar os processos de pesquisa e auto(trans)formação. O diálogo está sempre presente nesta dialética 
individual/coletiva; estabelecida na relação teoria/prática por meio da açãoreflexão-ação, perpassando e constituindo os diferentes movimentos.

Neste sentido, respeitando a dinamicidade dos/nos movimentos dos Círculos Dialógicos, eles vão surgindo, à medida que os diálogos vão acontecendo, na tessitura das relações com os sujeitos e com o contexto social, numa trama dialética em que uns estão presentes e imbricados nos outros, ainda que em alguns momentos um ou outro venha a ocorrer mais explicitamente.

Os movimentos que perpassam os CírCulos Dialógicos: uma trama dialética

Falar nos movimentos que compõem os Círculos Dialógicos é falar em uma trama que se organiza dialógica e dialeticamente e, por isso, não se pode mencionar nesse contexto a ideia de seguir uma sequência ou ordem preestabelecida, uma vez que "trata-se de uma proposta epistemológicopolítica eminentemente dialética e construtiva com vistas à transformação" (HENZ, 2015, p. 19). Nessa dinamicidade é possível que durante os diálogos que vão sendo tecidos com os outros, nos Círculos Dialógicos, alguns movimentos não apareçam tão explicitamente e outros se evidenciem mais, desde que suscitados e problematizados, a partir da realidade vivenciada pelos interlocutores/coautores.

Os diferentes movimentos estão imbricados em uma espiral ascendente, proativa e dialética, no qual todos se interligam e perpassam numa totalidade complexa, tornando-se condição uns dos outros, sem a necessária"passagem"ou"sobreposição" de uns sobre os outros. Também pode ocorrer de cada um desses movimentos se manifestar com maior (ou menor) força em momentos diferentes para a individualidade dos participantes, o que no coletivo grupal gera a dialética de todos os movimentos, interagindo simultaneamente em um mesmo encontro.

Embora não exista uma linearidade dos movimentos nos Círculos Dialógicos, o pesquisador líder tem um importante papel para que os movimentos aconteçam, sendo o mediador dos diálogos investigativo-formativos que vão surgindo no e com o grupo. Os elementos problematizadores para os diálogos são, inicialmente, propostos pelo pesquisador líder, podendo ser por meio de falas, imagens, trechos de filmes, fotos, músicas, enfim, questões problematizadoras que falem da realidade, dando dinamicidade aos movimentos. A escuta sensível e olhar aguçado, inclusive do pesquisador líder, é um dos primeiros movimentos que, normalmente, vão desencadeando os demais, sempre de maneira dialética e dialógica no, com e a partir das problematizações do grupo. 
Vale lembrar que algumas pesquisas de mestrado, realizadas por integrantes do Grupo de Estudos e Pesquisa Dialogus, bem como alguns capítulos de livro, vêm contribuindo na construção dessa proposta metodológica-epistemológico-política dos Círculos Dialógicos Investigativoformativos com e a partir do grupo, no qual boa parte desses movimentos que ora apresentamos já aparecem, mas ainda não contemplando os oito movimentos aqui mencionados. Ressalta-se, também, que a fundamentação da proposta epistemológico-política é uma construção cooperativa de conhecimentos, oriunda dos diálogos e reflexões que vêm emergindo nos encontros do grupo e nas pesquisas com os professores.

A representação gráfica dos diferentes movimentos dos Círculos Dialógicos utilizada logo abaixo, em forma de espiral, representa o movimento que vem sendo construído com o grupo de interlocutores/coautores que tem vivenciado essa proposta epistemológico-política na pesquisa de tese da autora desse artigo. A espiral é uma das representações utilizadas para representar a dinamicidade dos movimentos dos Círculos Dialógicos; no entanto, os leitores poderão encontrar diferentes versões da representação dos Círculos que, embora se tratando de representações diferenciadas, convergem sobre a mesma abordagem metodológica-epistemológicopolítica. O diferencial desta proposta é que:

Trabalhar com os Círculos Dialógicos Investigativo-formativos, como pesquisa e auto(trans)formação, possibilita reconhecer cada homem e cada mulher na sua singularidade e na sua capacidade de construir conhecimentos [...] sempre pelo diálogo e intersubjetivamente de uns com os outros (HENZ, 2015, p. 20-21).

Essa possibilidade de desvelamento da realidade, da transformação de si na relação com os outros e com o mundo, é simbolizada pelos movimentos dos Círculos Dialógicos numa espiral ascendente, com momentos de intersecção que, ao mesmo tempo em que dialogam entre si, ampliam a visão de mundo dos interlocutores/coautores que estão envolvidos. Nesta dinâmica, a vivência de cada um dos movimentos tem um papel fundamental para que o processo de auto(trans)formação ocorra dentro da processualidade dialética que representa, estando em permanentes e inacabadas (re)construções.

Assim, os oito movimentos que compõem e dão dinamicidade aos Círculos Dialógicos não surgem arbitrariamente, nem da imposição de alguém que passa a controlá-los; ao contrário, esses movimentos foram/ estão surgindo, a partir da caminhada construída com os professores e com 
os pesquisadores. Estes vêm dialogando e construindo, juntos, essa proposta epistemológico-política que, tal como os Círculos de Cultura, não pretende ser um "método", mas uma possível proposta epistemológico-política de pesquisa e auto(trans)formação com professores, para possibilitar a todos "ser mais" livres, autônomos e autores de si, das suas práxis e da sua história.

Em relação aos movimentos, é importante compreender que, além de não estabelecerem uma ordem a ser seguida, nem se apresentarem linearmente, eles podem acontecer em tempos, momentos e de múltiplas formas nos diferentes grupos, de acordo com a circularidade em que os diálogos se constituem. Nessa dinamicidade, tudo irá depender do contexto e participação dos interlocutores/coautores, de cujas narrativas irão emergir as temáticas geradoras, para que todos possam dizer a sua palavra (FIORI, 2014).

No decorrer do artigo, buscaremos fundamentar conceitualmente cada um dos movimentos. Em cada Círculo realizado, esses diferentes movimentos dialógicos e investigativo-formativos vêm aparecendo como dimensões importantes e constitutivas da auto(trans)formação permanente com e de professores, sendo eles:

Figura 01 - Movimentos dos Círculos Dialógicos Investigativo-formativos

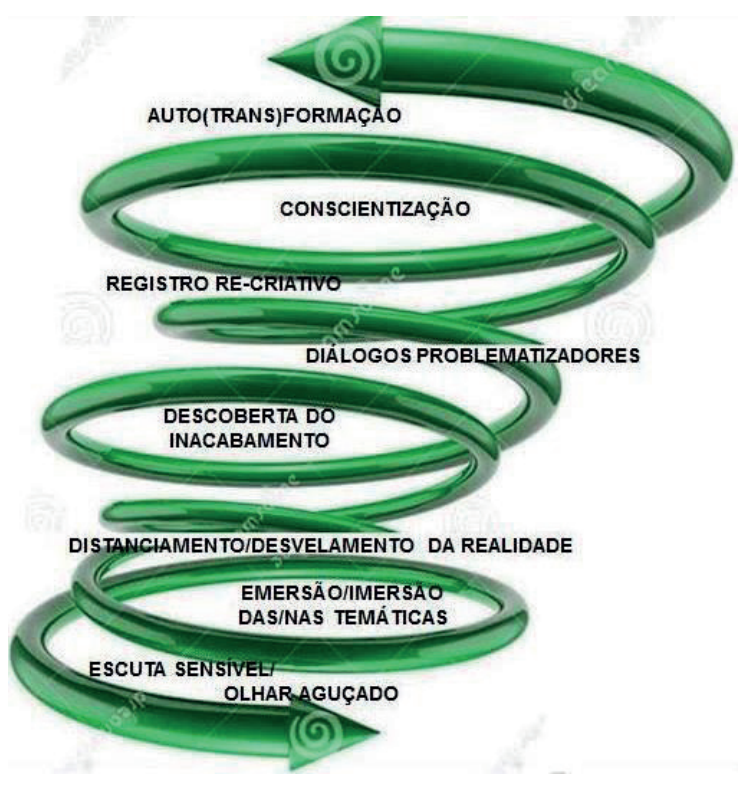

Fonte: Elaboração dos autores, 2016. 


\section{PARA INÍCIO DOS DIÁLOGOS: ESCUTA SENSÍVEL E OLHAR AGUÇADO}

Um dos movimentos que perpassa toda a espiral é a escuta sensível e o olhar aguçado; a atitude para ter uma escuta sensível é, primeiramente, educar a sensibilidade do olhar. O silêncio é condição sine qua non para a existência do diálogo; só no momento em que silencio a minha voz é que sou capaz de ver e escutar a voz do outro, criando uma ambiência para que ele diga sua palavra. Assim, a escuta é condição do diálogo, sem o qual nenhum dos demais movimentos é possível; é por meio da ação dialógica, que perpassa todos os demais movimentos, que se instaura a dinamicidade e vivacidade nos Círculos Dialógicos Investigativo-formativos.

Silêncio e diálogo podem, em um primeiro momento, até parecer dimensões contraditórias; no entanto, o silêncio é condição e disposição para escutar o outro e, a partir desta escuta atenta e sensível, conseguir lançar um olhar aguçado sob o dito e também o não dito (GADAMER, 1999) e dialogar com ele. No entanto, o silêncio não se refere ao silenciamento (que é uma ação de omissão ou indiferença), mas de respeito. $O$ silêncio é algo necessário para que se possa escutar o outro e, com ele, estabelecer uma relação respeitosa e dialógica. Neste sentido, "no processo da fala e da escuta a disciplina do silêncio a ser assumido com rigor e a seu tempo pelos sujeitos que falam e escutam é uma condição 'sine qua' da comunicação dialógica" (FREIRE, 1998, p. 131).

Os professores, ao exercerem o direito de dizerem a sua palavra e também o exercício da escuta do outro, vão aprendendo no Círculo Dialógico que apenas quando escutamos os outros é que aprendemos a falar com eles. Portanto, com Freire (1998) aprendemos que não se trata de falar aos outros como quem sabe tudo e transmite a eles, mas que é preciso primeiro escutar para aprender a falar com eles sobre o que faz sentido para suas experiências e esperanças.

O MOVIMENTO DE EMERSÃO/IMERSÃO DAS/NAS TEMÁTICAS: EMERGIR PARA IMERGIR

Buscando a coerência com as premissas dos Círculos de Cultura, durante a realização dos Círculos Dialógicos Investigativo-formativos, a partir da fala e da escuta dialógica, e também dialética, vão emergindo as temáticas geradoras a serem problematizadas no diálogo com o grupo, surgindo assim outro importante movimento: emersão/imersão das/nas temáticas. Propositalmente, são colocados nesse movimento os substantivos "emersão" e "imersão", tratando-se de um mesmo movimento, mas que apresentam significados que se complementam. A emersão das temáticas requer uma 
imersão nos contextos e práticas dos participantes interlocutores, pela escuta sensível e olhar aguçado. Atentos às temáticas que emergem da realidade é possível imergir nelas, de forma crítico-reflexiva, não como alguém que mergulha cegamente, mas que é capaz de perceber outras possibilidades que possam emergir a partir dela. Da capacidade do olhar aguçado criase a condição para o diálogo crítico-reflexivo sobre a realidade, com a possibilidade de inéditos viáveis (FREIRE, 2014).

As temáticas a serem problematizadas no diálogo com os interlocutores/coautores, na perspectiva dos Círculos Dialógicos, emergirão sempre da realidade concreta, da práxis, das relações no e com o mundo; "os temas, em verdade, existem nos homens, em suas relações com o mundo, referidos a fatos concretos" (FREIRE, 2014, p. 137). No entanto, a imersão só se torna possível na medida em que as temáticas que emergiram da escuta sensível, do olhar aguçado e, fundamentalmente, do diálogo, tenham algo a dizer sobre e para a realidade vivenciada, que sempre é datada, situada sócio-historicamente.

Com as temáticas que emergem nos Círculos Dialógicos, vêm à tona os motivos humanos e profissionais que nelas estão implicados e que, ainda, num primeiro momento não de forma consciente, são geradores do seu sentir/pensar/agir como professores, em seu estar sendo (FREIRE, 2014). Quando as temáticas que estão sendo emergem do diálogo e passam a ser problematizadas no e com o grupo, os sujeitos imergem nelas, adentram e implicam-se nas mesmas, discutindo, problematizando, dialogando para poder emergir delas, com consciência crítica e transformadora.

\section{DISTANCIANDO-SE PARA DESVELAR: MAIS UM MOVIMENTO}

Na dinamicidade do movimento dos Círculos Dialógicos acusa sua presença e requer seu reconhecimento outro movimento: o distanciamento/ desvelamento da realidade. $O$ distanciamento da realidade é condição para o seu desvelamento, pois somente quando nos distanciamos daquilo que é cotidiano, das ações que desenvolvemos repetitivamente sem a devida reflexão, é que "distanciando-se de seu mundo vivido, problematizando-o, 'descodificando-o' criticamente, no mesmo movimento da consciência o homem se redescobre como sujeito instaurador desse mundo de sua experiência" (FIORI, 2014, p. 20), conseguindo assim perceber a realidade e enxergá-la com maior clareza, refletindo sobre ela. Por vezes, é preciso tomar distância do contexto para reconhecê-lo e, assim, desvelá-lo e atuar sobre ele.

Esse é um movimento de suma importância nos Círculos Dialógicos, pois requer e possibilita escuta sensível, olhar aguçado, imersão/emersão na 
realidade. Distanciar-se é “[...] un cierto modo de relación con la realidad, es una distancia que se establece con la realidad. Uno se desprende de la realidad para representársela. Representar quiere decir presentar outra vez la realidad [...]"1 (FERRY, 2004, p. 56), para assim, pelo distanciamento, olhar de novo, olhar criticamente, decodificar, conscientizar-se e descobrir-se inacabado, com possibilidades de intervir para (auto)transformar(-se). Paradoxalmente, quanto mais me afasto, mais consigo adentrar na realidade, na temática geradora e intervir sobre ela.

Um exemplo de desvelamento da realidade foi relatado por Freire em uma de suas andarilhagens em São Tomé, na África, com a alfabetização de adultos, quando menciona uma importante recordação:

Entre as inúmeras recordações que guardo da prática dos debates dos Círculos de Cultura de São Tomé, gostaria de referir-me agora a uma que me toca de modo especial. Visitávamos um Círculo numa pequena comunidade pesqueira chamada Monte Mário. [...] O grupo de alfabetizandos olhava em silêncio a codificação. Em certo momento, quatro entre eles se levantaram, como se tivesse combinado, e se dirigiram até a parede em que estava fixada a codificação (o desenho do povoado). Observaram a codificação de perto, atentamente. Depois, dirigiram-se à janela da sala onde estávamos. Olharam o mundo lá fora. Entreolharam-se, olhos vivos, quase surpresos, e, olhando mais uma vez a codificação, disseram:“É Monte Mário. Monte Mário é assim e não sabíamos". Através da codificação, aqueles quatro participantes do Círculo "tomavam distância" do seu mundo e o reconheciam. Em certo sentido, era como se estivessem "emergindo" do seu mundo, "saindo" dele, para melhor conhecê-lo (FREIRE, 2011, p. 57).

Ao tomar distância do próprio mundo começamos a vivenciar o processo de reconhecimento do eu como parte do contexto, havendo assim o desvelamento da realidade. Desvelar significa "tirar o véu", desencobrir, descortinar, existenciar-se, autodesvelar-se como seres históricos; processo esse que é feito individualmente, mas a partir da coletividade, do trabalho com o outro, tornando-se sujeitos atuantes do seu próprio desvelamento, mesmo porque esse movimento não acontece de um sujeito para o outro, mas na relação de uns com os outros. Assim, o contexto vai sendo "re-olhado" e ressignificado, apontando outras possibilidades; e todos se reconhecem e assumem como sujeitos e coautores dessa processualidade desveladora e epistemológico-política. 


\section{DESCOBRIR-SE INACABADO PARA PROSSEGUIR OS DIÁLOGOS}

Ao olhar e decodificar a realidade os sujeitos coautores descobrem-se como seres condicionados, mas não determinados como fatalidade histórica. Esse "dar-se conta" encaminha o processo dialógico para outro movimento: a descoberta do inacabamento. Somente quando percebemos que a realidade vai muito além do que está dado é que nos damos conta do nosso inacabamento e da necessidade de estarmos constante e permanentemente aprendendo.

Ao pensar a docência, o momento da descoberta de si como ser inacabado em constante processo aprendente é um movimento importante para impulsionar na direção de aprender com o outro, com os colegas professores, com outros profissionais e, intencionalmente, com os estudantes que vivenciam esse processo, reconhecendo-se "[...] na inconclusão dos homens e na consciência que dela têm. Daí que seja a educação um quefazer permanente. Permanentemente, na razão da inconclusão dos homens e do devenir da realidade" (FREIRE, 2014, p. 101-102).

A consciência da inconclusão não é um processo inato, mas que vai se construindo na relação com os outros, na problematização da realidade, da sua própria práxis, a partir da descoberta e compreensão de que a realidade é sócio-histórica e, como tal, pode ser transformada pela ação-reflexão de homens e mulheres. Reconhecem-se, assim, também a si mesmos como sujeitos em permanente processo de auto(trans)formação. Ao reconhecerse condicionado historicamente, cada sujeito coautor(a) também pode reconhecer-se como não determinado, com possibilidades de vir a ser, transformando a si mesmo e a realidade que o condiciona.

\section{Perpassando os movimentos dos CírRulos: os diálogos PROBlematizadores}

A consciência da inconclusão, do inacabamento, vai se constituindo por meio do grupo que dialoga, apontando para outro movimento central nos Círculos: os diálogos problematizadores. São eles - os diálogos problematizadores - os responsáveis por dinamizar todos os movimentos dos Círculos Dialógicos Investigativo-formativos, não estando alocados em uma ordem pré-estabelecida, vindo a priori ou a posteriori de um único movimento; ele se constitui dispositivo potencializador de toda dinamicidade dos encontros grupais. No entanto, pode acontecer que, nos movimentos iniciais, os diálogos que vão sendo construídos não se apresentem de forma tão problematizadora, o que vai progredindo na medida em que as reflexões críticas vão surgindo nos demais movimentos da circularidade da espiral. 
A processualidade dos movimentos, a partir da escuta atenta, sensível e do olhar aguçado, provoca a emersão/imersão consciente da realidade, por meio das temáticas geradoras, despertando nos interlocutores/coautores a descoberta como seres inacabados, sempre por meio dos diálogos problematizadores. Esses vão sendo tecidos no e com o grupo, durante a realização dos Círculos Dialógicos e, quanto mais a ação-reflexão-ação ganha rigorosidade, mais se consegue ler criticamente a realidade e a própria práxis educativa para assumi-la como inacabada e capaz de ser mudada.

Esse desvelamento, como processo de decodificação e leitura crítica da realidade, vai acontecendo quando os diálogos se estabelecem de forma eminentemente cooperativa e problematizadora, entrelaçando-se com os demais movimentos, buscando construir cooperativamente uma análise crítica sobre a realidade sócio-histórico-cultural. Por esse motivo é que, na perspectiva dos Círculos Dialógicos, não podemos categorizar uma ordem imutável para os movimentos, entendendo que muitos deles se entrelaçam dialeticamente em vários momentos, por meio de uma circularidade ascendente e proativa, "[...] como processo dialético-problematizador. $\mathrm{Ou}$ seja, através do diálogo podemos olhar o mundo e a nossa existência em sociedade como processo, algo em construção, como realidade inacabada e em constante transformação" (ZITKOSKI, 2010, p. 117).

Assim, o movimento dos diálogos problematizadores não acontece somente após a descoberta do inacabamento, mas perpassa toda dinamicidade dos Círculos Dialógicos. Ao dialogar, cada um e cada uma diza sua palavra, expõe o seu mundo ou a visão que possui dele; vai percebendo-se como ser de cultura, ser de processo, capaz, não apenas de viver a realidade que está posta, mas de intervir sobre ela.

\section{REGISTRAR PARA (RE)CRIAR: O REGISTRO RE-CRIATIVO}

Outro movimento de fundamental importância para a dinâmica dos Círculos Dialógicos Investigativos-formativo é o registro; não o registro que reproduz ou apenas faz apontamentos, mas aquele que é (re)criado, a partir da reflexão crítica sobre a prática: o registro re-criativo.

Este tipo de registro é uma construção individual, mas surge na coletividade, a partir dos diálogos que vão sendo tecidos nos Círculos Dialógicos, os quais vão emergindo as situações-limites que se apresentam na práxis docente. Cada nova situação-limite vai mobilizando a pensar criticamente sobre cada nova situação levantada, problematizada, o que impulsiona outras decisões e escolhas. 
Nesse movimento, a consciência de cada sujeito vai buscando perfazer-se, auto(trans)formar-se, processo esse que não surge no espontaneísmo, mas na ação-reflexão-ação, mobilizada, muitas vezes, pelo movimento do distanciamento necessário para o registro re-criativo. Nesta perspectiva, o registro não se constitui nunca em uma escrita desconectada da realidade de quem a vivencia; ao contrário, só se registra aquilo que, de alguma forma, tenha representado ou significado algo; registro, este, que diga algo de e para nós mesmos.

O registro re-criativo, neste sentido, não se limita apenas a descrever e repetir o fato acontecido, descolado de uma reflexão mais atenta, mesmo porque "[...] guardo em meu corpo consciente e falante, ao pensar, a possibilidade de escrever da mesma forma que, ao escrever, continuar a pensar e a repensar o pensando-se como o já pensado" (FREIRE, 2013, p. 26). A primeira forma de registro e de pronúncia do mundo se dá pela palavra; é pronunciando o mundo que somos capazes de (re)dizê-lo, registrá-lo de outra maneira, de uma forma (re)criativa. O ato de registrar provoca impressões, reflexões, dúvidas, angústias que, ao fazer o registro, tanto pela palavra falada quanto pela palavra escrita, vão sendo levantadas individualmente e no diálogo com os outros que, por vezes, compartilham de alguns desses sentimentos, pronúncias/narrativas ou as ressignificam. Esse movimento denota a importância de registrar de forma mais sistematizada, pela escrita, o que vai sendo observado, vivenciado e dialogado. Por isso mesmo,

Precisamos exercitar a capacidade de observar, registrando o que observamos. Mas registrar não se esgota no puro ato de fixar com pormenores o observado tal qual para nós se deu. Significa também, e ao lado deste registro, arriscar-nos a fazer algumas observações críticas e avaliativas a que não devemos, contudo, emprestar ares de certeza. [...] A cada estudo e a cada reestudo que se faça, em diálogo com os educandos, ratificações e retificações se vão fazendo (FREIRE, 2013, p. 164).

A partir do movimento do registro re-criativo emerge a possibilidade de se ratificar ou retificar a práxis que vai constituindo-se em um que fazer com tomada de consciência e intencionalidade, sendo intermediado pela ação dialógica crítico-reflexiva. O exercício do registro possibilita, assim, a reflexão sobre o feito que, ao pensá-lo, pode ser refeito, recriado, recriando o antes feito de forma diferente do que havia sido:"por isso escrever é preciso, para encontrar-se a si mesmo sendo mais forte do que se é, para a longa e tortuosa busca do Outro" (MARQUES, 2011, p. 45).

Por meio do registro re-criativo tem-se a possibilidade de ir se reinventando, se autocompreendendo, tomando consciência do movimento 
da sua própria aprendizagem e auto(trans)formação. Além disso, o desafio do registro escrito nos faz retomar e "re-olhar" o recordado e dito, fazendo comparações, relações, ressignificações e possibilidades de novas perspectivas. Assim, essas ações-reflexões-ações vão nos inquietando e impulsionando a tomada de consciência nas relações que estabelecemos com nossos estudantes, com nossos colegas, nossos fazeres, nossa ação pedagógica. O registro é, assim, um movimento importante que vai sistematizando e dando dinamicidade e aprofundamento a outro movimento presente em toda a circularidade dos diálogos no grupo: o da conscientização.

\section{DA CONSCIENTIZAÇÃO À AUTO(TRANS)FORMAÇÃO: MAIS UM IMPORTANTE MOVIMENTO}

Outro importante movimento se refere à conscientização dos sujeitos coautores, que vai se construindo a partir da vivência e interlocução com os demais sujeitos. A partir de uma inicial tomada de consciência, cada sujeito coautor vai percebendo que ele foi e é sujeito de suas transformações, reconhecendo-se como ser inacabado, em constante processo aprendente. No entanto, apesar de um momento muito importante para a conscientização,

Esta tomada de consciência não é ainda a conscientização, porque esta consiste no desenvolvimento crítico da tomada de consciência. A conscientização implica, pois, que ultrapassemos a esfera espontânea de apreensão da realidade, para chegarmos a uma esfera crítica na qual a realidade se dá como objeto cognoscível e na qual o homem assume uma posição epistemológica. A conscientização é, neste sentido, um teste de realidade. Quanto mais conscientização, mais se desvela a realidade, mais se penetra na essência fenomênica do objeto, frente ao qual nos encontramos para analisá-lo (FREIRE, 2008, p. 30).

Somente quando o desenvolvimento crítico da tomada de consciência vai desvelando a realidade e, assim, atuando sobre ela, passando de uma concepção ingênua a uma concepção crítica, é que se pode falar em conscientização. A conscientização é mais do que uma tomada de consciência, ou algo que fica apenas no âmbito subjetivo e das ideias; ela leva a superar concepções mágicas e ingênuas e, pela desmitificação que se dá pelo diálogo problematizador e reflexivo, possibilita a inserção crítica e transformadora dos participantes na realidade, preparando-os para o compromisso com a luta pela re-humanização da educação e do mundo.

O ato de ação-reflexão-ação que constitui a práxis é o que caracteriza a conscientização como compromisso histórico, onde os sujeitos inseremse na história como seres atuantes que fazem, refazem, se refazem, 
transformando a si e ao mundo. Por isso mesmo, "a conscientização não pode existir fora da práxis, ou melhor, sem o ato ação - reflexão. Esta unidade dialética constitui, de maneira permanente, o modo de ser ou de transformar o mundo que caracteriza os homens" (FREIRE, 2008, p. 30). Essa perspectiva histórica da possibilidade de conscientização para ser mais a cada dia, de estar constantemente aprendendo, reconhecendo-se como seres inacabados em constante processo de estar sendo é que impulsiona outro movimento que vai se constituindo nos Círculos Dialógicos Investigativo-formativos: $a$ auto(trans)formação.

\section{O movimento da Auto(trans) formação nos CírCulos DialóGıcos}

A auto(trans)formação é o movimento que vai se potencializando e constituindo em todos os demais: a escuta sensível e o olhar/aguçado; a emersão/imersão das/nas temáticas; o distanciamento/desvelamento da realidade; a descoberta do inacabamento; os diálogos problematizadores; o registro re-criativo e a conscientização são movimentos que vão contribuindo para que o processo de auto(trans)formação aconteça, na mesma dialética que essa se faz necessária para a viabilidade dos outros movimentos. Conforme mencionado anteriormente, durante a realização dos Círculos Dialógicos Investigativo-formativos esses movimentos estão uns imbricados nos outros e podem ocorrer aleatoriamente, embora um dos principais objetivos da pesquisa com os professores é a sua auto(trans)formação, tanto do pesquisador líder quanto dos sujeitos coautores envolvidos na pesquisa, em permanente cooperação uns com os outros. Nesta dinamicidade,

a auto(trans)formação permanente de professores se dá por meio de uma circularidade em espiral ascendente proativa que se movimenta dentro da condição ontológica do inacabamento humano em busca do"ser mais" (FREIRE, 2011), o que só é possível pelo diálogo com os outros e com o mundo. Pela dialética ação-reflexão-ação constitui-se um movimento cooperativo entre homens e mulheres que passam a perceber-se sujeitos no mundo, imersos em uma realidade que os condiciona, mas também descubram que são capazes de transformá-la (HENZ, 2015, p. 20).

Essa capacidade de transformar-se, de auto(trans)formar-se vai envolvendo e empoderando os sujeitos participantes da pesquisa, tanto pesquisadores quanto coautores. O prefixo auto aqui defendido não se refere a um eu isolado, mas um eu com os outros; sujeitos conscientes como seres inacabados, que aprendem e auto(trans)formam-se em comunhão. Nessa (inter)relação, os coautores vão fazendo-se e refazendo-se, também na/pela palavra, no trabalho, na ação-reflexão-ação. 
Quando ocorre o reconhecimento desse movimento auto(trans) formativo - o que não ocorre em um momento único para os diferentes participantes/coautores - vão emergindo/constituindo-se novos desafios, novas dificuldades, novas possibilidades: renovam-se e ressignificam-se a escuta sensível, o olhar aguçado, a emersão/imersão das temáticas e os demais movimentos, mantendo os Círculos Dialógicos como um espaço vivo e em permanente movimento em espiral ascendente, proativa e dialética. Daí a complementaridade do título atribuído aos Círculos Dialógicos onde se engendram todos esses movimentos e muitos outros vão aparecendo: Círculos Dialógicos Investigativo-formativos.

No entanto, o significado dos Círculos, neste contexto, por serem eminentemente dialógicos, não representam a ideia de um ciclo que inicia e completa seu curso, retornando sempre ao mesmo ponto. Ao contrário, os mesmos fundamentam-se na perspectiva de movimentos que se constituem e reconstituem pelo dizer a palavra de todos, sem que alguém assuma papel de superioridade, mas todos aprendem em reciprocidades (FIORI, 2014), por meio da ação dialógico-reflexiva.

Por essa razão, os Círculos Dialógicos Investigativo-formativos “[...] configuram-se em espaços e dispositivos de estudos em que pesquisadores e sujeitos interlocutores têm a possibilidade de dialogar abertamente" (HENZ; FREITAS, 2015, p. 81), em cujos movimentos engendram-se diferentes dizeres e fazeres, a partir da escuta e da manifestação da palavra, movimento pelo qual vai se dando início a investigação do próprio contexto, problematizando a realidade, num processo permanente de ação-reflexãoação. Ao capturar a concretude sócio-histórico-cultural, problematizando-a, refletindo criticamente sobre ela, construindo outras possibilidades para sua transformação, podemos dizer que estamos vivenciando permanentes e inacabados processos de auto(trans)formação.

PAULO FREIRE FROM RESEARCH PERSPECTIVES: THE FORMATIVE-INVESTIGATIVE DIALOGICAL CIRCLES AS A POSSIBILITY OF REINVENT THE CIRCLES OF CULTURE AND SELF-DIRECTED IN-SERVICE LEARNING WITH TEACHERS

ABSTRACT: This article aims to socialize the constructions carried out within the scope of the research, based on the theoretical contributions of Paulo Freire. Inspired by the Circles of Culture (Freire, 2014), we (re)create the Investigative-Formative Dialogical 
Circles as an epistemological-political proposal of research, from eight different movements that constitute them: sensitive listening and pointed look; the emersion/ immersion of the themed; the detachment/ unveiling of reality; the discovery of unfinished; the problematizing dialogues; the re-creative record; the awareness and self (trans)formation, which is becoming stronger and constituting itself in all other movements. During the realization of the Dialogical Circles with the teachers, these movements are developing dialogically and dialectically, aiming always at the self (trans) formation of both the leading researcher and the co-authors involved in the research.

KEYwORDS: Dialogical Circles focused on research and training. In-service self-directed learning. Research. Circles of Culture.

PAULO FREIRE EN LA INVESTIGACIÓN: LOS CÍRCULOS DIALÓGICOS INVESTIVATIVOFORMATIVOS COMO POSSIBILIDAD DE REINVENCIÓN DE LOS CÍRCULOS DE CULTURA Y AUTO(TRANS)FORMACIÓN PERMANENTE CON PROFESORES

RESUMEN: Este artículo tiene como objetivo divulgar y compartir las construcciones realizadas en el ámbito de la investigación, tomando como base las aportaciones teóricas de Paulo Freire. Inspirados por los Círculos de Cultura (FREIRE, 2014), (re) creamos los Círculos Dialógicos Investigativo-formativos como una propuesta epistemológico-política de investigación, a partir de ocho diferentes movimientos que los constituyen: la audición sensible y la mirada/aguzada; la emersión/inmersión de las/ en las temáticas; el distanciamiento/desvelamiento de la realidad; el descubrimiento de lo inacabado; los diálogos problematizadores; el registro re-creativo; la concienciación y la auto(trans)formación, que se va potencializando y constituyendo en todos los demás movimientos. Durante la realización de los Círculos Dialógicos con los profesores, esos movimientos se van tramando dialógica y dialécticamente, procurando siempre la auto(trans)formación, tanto del investigador líder como de los sujetos coautores involucrados en la investigación.

Palabras Clave: Círculos dialógicos Investigación-formación. Auto(trans)formación permanente. Investigación. Círculos de Cultura.

\section{NOTAS}

1 [...] uma certa forma de relação com a realidade, é uma distância que se estabelece com a realidade. A pessoa se "desprende" da realidade para representá-la. Representar significa apresentar outra vez a realidade (FERRY, 2004, p. 56). 


\section{REFERÊNCIAS}

BRANDÃO, C. R. Círculo de Cultura. In: STRECK, D. R.; REDIN, E.; ZITKOSKI, J. (Org.). Dicionário Paulo Freire. 2. ed. Belo Horizonte: Autêntica Editora, 2010.

. O que é método Paulo Freire. 34. ed. São Paulo: Brasiliense, 2013.

FERRY, G. Pedagogía de la formación. Buenos Aires: Centro de Publicaciones Educativas y Material Didáctico, 2004.

FIORI, E. M. Prefácio: Aprender a dizer a sua palavra. In: FREIRE, P. Pedagogia do Oprimido. 56. ed. Rio de Janeiro: Paz e Terra, 2014.

FREIRE. P. Pedagogia da Autonomia: saberes necessários à prática Educativa. 7. ed. São Paulo: Paz e Terra, 1998.

; FAUNDEZ, A. Por uma Pedagogia da Pergunta. 5. ed. Rio de Janeiro: Paz e Terra, 2002.

. Conscientização: teoria e prática da libertação - uma introdução ao pensamento de Paulo Freire. 3. ed. 2. São Paulo: Centauro, 2008.

. A importância do ato de ler: em três artigos que se completam. 51. ed. São Paulo: Cortez, 2011. (Coleção questões da nossa época). v. 22..

. Professora sim, tia não: cartas a quem ousa ensinar. 24. ed. Rio de Janeiro: Paz e Terra, 2013.

. Pedagogia do Oprimido. 56. ed. Rio de Janeiro: Paz e Terra, 2014.

GADAMER, H. G. Verdade e Método: traços fundamentais de uma hermenêutica filosófica. 3. ed. Editora Vozes: Petrópolis, 1999.

HENZ, C. I. Círculos Dialógicos Investigativo-formativos e Auto(trans)formação Permanente de Professores. In: HENZ, C. I.;TONIOLO, J. M. S. A. (Org.). Dialogus: círculos dialógicos, humanização e auto(trans)formação de professores. São Leopoldo: Oikos, 2015.

HENZ, C.; FREITAS, L. M. Círculos Dialógicos Investigativo-formativos e Auto(trans) formação Permanente de Professores. In: HENZ, C. I.; TONIOLO, J. M. S. A. (org.). Dialogus: círculos dialógicos, humanização e auto(trans)formação de professores. São Leopoldo: Oikos, 2015.

JOSSO, M. C. Caminhar para si. Porto Alegre: EDIPUCRS, 2010.

MARQUES, M. O. Escreveré preciso: o princípio da pesquisa. 2. ed. Petrópolis, RJ:Vozes, 2011.

ZITKOSKI, J. Diálogo/Dialogicidade. In: STRECK, D. R.; REDIN, E.; ZITKOSKI, J. (Org.). Dicionário Paulo Freire. 2. ed. Belo Horizonte: Autêntica, 2010. 
Joze Medianeira dos Santos de Andrade Toniolo: Doutoranda em Educação (PPGE/UFSM), professora do Instituto Federal de Educação, Ciência e Tecnologia Farroupilha (IFFar) e pesquisadora do Grupo de Estudos e Pesquisa Dialogus: educação, formação e humanização com Paulo Freire. Tem experiência na área de Educação, principalmente nos seguintes temas: formação de professores, trabalho docente, dialogicidade, amorosidade e Paulo Freire.

E-mail: jozemsa@gmail.com

Celso llgo Henz: Doutor em Educação (UFRGS), professor associado 2 da Universidade Federal de Santa Maria (UFSM) e pesquisador do Programa de Pós-Graduação em Educação (PPGE/UFSM), na Linha de Pesquisa: Formação, Saberes e Desenvolvimento Profissional. É, também, líder do Grupo de Estudos e Pesquisa Dialogus: educação, formação e humanização com Paulo Freire, registrado junto à base do CNPq. Tem experiência na área de Educação, com ênfase em Educação, atuando principalmente nos seguintes temas: formação de professores, educação humanizadora, cidadania, leitura de mundo/leitura da palavra e Paulo Freire.

E-mail: celsoufsm@smail.com 